\title{
Recurrent Lip Basal Cell Carcinoma
}

National Cancer Institute

\section{Source}

National Cancer Institute. Recurrent Lip Basal Cell Carcinoma. NCI Thesaurus. Code C8213.

Reemergence of basal cell carcinoma of the lip after a period of remission. 